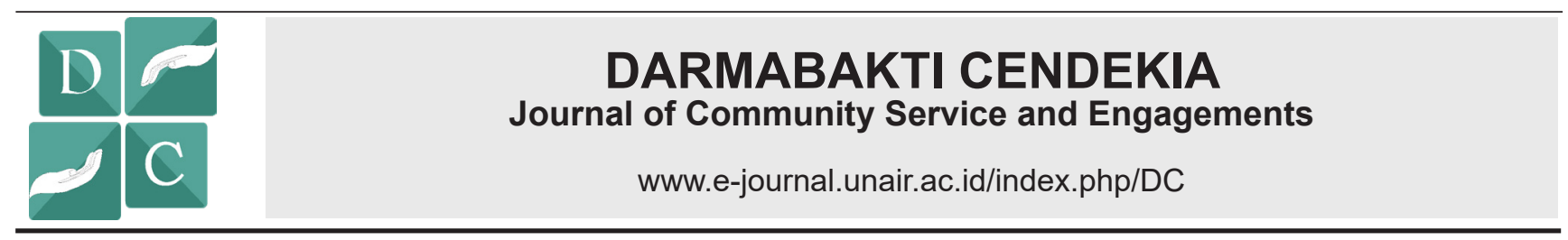

\title{
SOCIALIZATION OF SELF CARE TOGA AND ACUPRESSURE AT GADING HEALTH CENTER IN SURABAYA
}

\author{
SOSIALISASI ASUHAN MANDIRI TOGA DAN AKUPRESUR DI \\ PUSKESMAS GADING SURABAYA
}

Scope:

Health

\author{
Ario Imandiri ${ }^{1 *}$, Maya Septriana ${ }^{1}$ \\ ${ }^{1}$ Department of Health, Faculty of Vocational Studies, Universitas Airlangga, Surabaya-Indonesia
}

\begin{abstract}
A B S T R A C T
Background: The community made various efforts to be able to overcome the health complaints that they experienced, whether it was done alone by people who experienced health complaints or by healthy families. Efforts made by the community in overcoming health complaints suffered include self-treatment based on the knowledge they have by massage or consuming materials or processed from plants or animals, conducting consultations or examinations on traditional and medical health facilities, and can also bring in officers home health. Purpose: Increasing public knowledge regarding how to process traditional medicines and independent acupressure. Method: Providing knowledge to the Independent Care Cadres of Gading Surabaya Health Center regarding how to process traditional medicines and independent acupressure through demonstration of making traditional medicines and independent acupressure. Results: The activity of Independent Care of Family Medication and Acupressure Care for Cadre groups in Gading Surabaya Health Center went well. The cadre welcomed the program and they participated in the coaching activities actively. Conclusion: The Independent Care of Family Medication and Acupressure care for Cadre groups coaching program in Gading Surabaya Health Center is very beneficial for the community in overcoming minor ailments without taking chemical drugs.
\end{abstract}

\section{A B S T RAK}

Latar belakang: Masyarakat melakukan berbagai upaya untuk dapat mengatasi keluhan kesehatan yang dialaminya, baik itu dilakukan sendiri oleh orang yang mengalami keluhan kesehatan maupun oleh keluarganya yang sehat. Upaya yang dilakukan masyarakat dalam mengatasi keluhan kesehatan yang dideritanya antara lain mengobati diri sendiri berdasarkan pengetahuan yang dimilikinya dengan cara pemijatan maupun mengkonsumsi bahan atau olahan yang berasal dari tanaman atau hewan, melakukan konsultasi atau pemeriksaan pada fasilitas kesehatan tradisional maupun medis, serta dapat juga mendatangkan petugas kesehatan ke rumah. Tujuan: Meningkatkan pengetahuan masyarakat terkait cara pengolahan obat tradisional dan akupresur mandiri. Metode: Memberikan pengetahuan kepada Kader Asuhan Mandiri Puskesmas Gading Surabaya terkait cara pengolahan obat tradisional dan akupresur mandiri melalui demonstrasi pembuatan obat tradisional dan akupresur mandiri. Hasil: Kegiatan pembinaan Asuhan Mandiri Tanaman Obat Keluarga dan Akupresur terhadap kelompok Kader di Puskesmas Gading Surabaya berjalan dengan baik. Kader menyambut dengan baik kegiatan tersebut dan berpartisipasi aktif dalam kegiatan pembinaan tersebut. Kesimpulan: Kegiatan pembinaan Asuhan Mandiri Tanaman Obat Keluarga dan Akupresur terhadap kelompok Kader di Puskesmas Gading Surabaya sangat bermanfaat bagi masyarakat dalam mengatasi penyakit ringannya tanpa minum obat kimia.

\section{ART I CLE INFO}

Recieved 27 February 2019

Accepted 11 June 2019

Online 28 June 2019

*Correspondence(Korespondensi): Ario Imandiri

E-mail:

ario.imandiri@vokasi.unair.ac.id

Keywords:

Traditional medicine;

Acupressure; Independent care

Kata kunci:

Obat tradisional; Akupresur;

Asuhan mandiri 


\section{PENDAHULUAN}

Kesehatan merupakan kebutuhan mendasar dari manusia yang menjadi tanggung jawab seseorang sebagai anggota masyarakat dan didukung oleh negara dalam bentuk berbagai program kesehatan. Adanya permasalahan kesehatan di masyarakat dapat mempengaruhi upaya pembangunan manusia Indonesia seutuhnya.

Kesehatan dipengaruhi oleh berbagai faktor. Faktor yang mempengaruhi tingkat kesehatan masyarakat antara lain adalah faktor pendidikan, pengetahuan, ketersediaan fasilitas pelayanan kesehatan serta faktor tingkat kesejahteraan atau tingkat kemiskinan masyarakat. Berdasarkan data Profil Kesehatan Indonesia tahun 2017, Indeks Keparahan Kemiskinan Jawa Timur pada bulan September 2017 sebesar 0,56 sedangkan Indeks Keparahan Kemiskinan Indonesia pada bulan yang sama adalah sebesar 0,46. Berdasarkan data Statistik kesehatan Provinsi Jawa Timur tahun 2017, sebanyak 31,71\% penduduk Jawa Timur mengalami keluhan kesehatan.

Keluhan kesehatan terdiri atas keluhan akibat gangguan kondisi fisik, kondisi jiwa, serta akibat dampak dari kecelakaan maupun hal lain. Data statistik tersebut dapat menggambarkan kondisi kesehatan penduduk Provinsi Jawa Timur secara umum yang disebabkan suatu penyakit atau penyebab tertentu.

Masyarakat melakukan berbagai upaya untuk dapat mengatasi keluhan kesehatan yang dialaminya, baik dilakukan pasien yang mengalami keluhan kesehatan maupun oleh keluarga pasien. Upaya yang dilakukan masyarakat dalam mengatasi keluhan kesehatan yang dideritanya antara lain mengobati diri sendiri berdasarkan pengetahuan yang dimilikinya dengan cara pemijatan maupun mengkonsumsi bahan atau olahan yang berasal dari tanaman atau hewan, melakukan konsultasi atau pemeriksaan pada fasilitas kesehatan tradisional maupun medis, serta dapat juga mendatangkan petugas kesehatan ke rumah.

Terapi dengan teknik akupunktur terbukti sangat membantu mengurangi dan mengatasi penyakit, serta mengurangi dosis obat kimia, terutama pada lansia. Terapi akupunktur adalah terapi menggunakan jarum akupunktur pada titik akupunktur yang harus dilakukan oleh tenaga terdidik dan terlatih. Untuk masyarakat umum dapat diajarkan teknik akupresur. Akupresur merupakan teknik pemijatan pada titik akupunktur. The National Institutes of Health Consensus Panel on Acupuncture merekomendasikan penggunaan akupunktur untuk dapat mengurangi dosis obat (NIH Consensus Conference, 1998).

Terapi akupunktur telah masuk pada pedoman penatalaksanaan pasien geriatri. Beberapa pedoman yang menyertakan terapi akupunktur di dalamnya antara lain adalah Global Guideline Managing Older People with Type 2 Diabetes (International Diabetes Federation, 2013) untuk kasus diabetes tipe 2, Guidance on the Management of Pain in Older People (British Geriatrics Society, 2013) untuk kasus nyeri, serta Clinical Guidelines on Geriatric Urinary Incontenence (Geriatrics subcommittee, 2003) untuk kasus inkontinensia urin.

Tanaman obat yang dapat mengatasi penyakit degenerative telah lama digunakan oleh masyarakat Indonesia secara turun menurun. Masyarakat menggunakan tanaman obat tersebut selain untuk diri sendiri, juga untuk keluarganya. Beberapa contoh tanaman obat yang digunakan masyarakat untuk mengatasi kelainan degeneratifnya adalah kayu manis yang mengandung antioksidan. Kayu manis ini dapat mengatasi penyakit degenerative seperti diabetes, hipertensi, kanker, serta jantung coroner (Biofarmaka IPB, 2015).

Melalui kegiatan Pengabdian pada Masyarakat, peneliti melaksanakan pembinaan terkait teknik akupresur mandiri yang sederhana untuk mengatasi dan meringankan keluhan penyakit. Dengan memahami Teknik akupresur, diharapkan masyarakat dapat mengatasi keluhan penyakit sederhananya serta mengurangi mengkonsumsi obat kimia.

\section{METODE}

Metode yang digunakan adalah pembinaan terhadap kelompok Kader Asuhan Mandiri di Puskesmas Gading Surabaya. Pada kelompok kader yang semuanya adalah ibu rumah tangga ini dilakukan pembinaan terkait Asuhan Mandiri Tanaman Obat Keluarga dan Akupresur di Puskesmas Gading Surabaya.

Masyarakat diajarkan bagaimana membuat obat tradisional yang bahannya dapat ditanam di halaman atau area di sekitar tempat tinggal masyarakat. Pembinaan pembuatan obat tradisional dilakukan dengan cara mendemonstrasikan secara langsung cara mengenali bahan tanaman obat tradisional, pemilihan bahan tanaman obat tradisional yang baik dan benar, pengolahan obat tradisional dengan baik dan benar, serta cara penyajian yang baik dan benar.

Selain kegiatan pembinaan terkait Tanaman Obat Keluarga, juga dilakukan kegiatan pembinaan terkait Akupresur mandiri. Kader diberikan pengetahuan dasar dan sederhana terkait akupresur. Selanjutnya kader diajarkan mencari titik akupunktur yang dapat ditekan untuk mengatasi penyakit tertentu. Setelah kader telah memahami cara mencari titik akupunktur yang akan ditekan, kader diajarkan teknik penekanan sehingga dapat bermanfaat dalam mengurangi keluhan atau gejala yang dialaminya. 


\section{HASIL DAN PEMBAHASAN}

Kegiatan pembinaan Asuhan Mandiri Tanaman Obat Keluarga dan Akupresur terhadap kelompok Kader di Puskesmas Gading Surabaya berjalan dengan baik. Kader menyambut dengan baik kegiatan tersebut dan berpartisipasi aktif dalam kegiatan pembinaan tersebut. 35 orang kader hadir dan berpartisipasi aktif dalam kegiatan demonstrasi pembuatan obat tradisional dan demonstrasi akupresur mandiri.

Kader sangat tertarik dan mau berpartisipasi aktif karena merasa informasi terkait cara pengolahan obat tradisional dan akupresur mandiri ini sangat bermanfaat bagi diri sendiri, keluarga dan orang dilingkungannya. Kader akan mengajarkan cara pengolahan obat tradisional dan akupresur mandiri yang diperolehnya ini kepada keluarga dan orang disekitarnya, agar keluarga dan orang disekitarnya dapat mengurangi keluhan penyakit ringannya tanpa minum obat kimia.

\section{KESIMPULAN DAN SARAN}

Kegiatan pembinaan Asuhan Mandiri Tanaman Obat Keluarga dan Akupresur terhadap kelompok Kader di Puskesmas Gading Surabaya sangat bermanfaat bagi masyarakat dalam mengatasi penyakit ringannya tanpa minum obat kimia. Diharapkan pembinaan semacam ini dapat dilakukan pula kepada kader di seluruh puskesmas di Indonesia agar masyarakat dapat mengurangi keluhan penyakit ringannya tanpa minum obat kimia.

\section{UCAPAN TERIMA KASIH}

Kami mengucapkan banyak terimakasih kepada Dinas Kesehatan Kota Surabaya dan Puskesmas Gading Surabaya yang telah melaksanakan kegiatan ini. Penulis menyatakan tidak ada konflik kepentingan dengan pihak-pihak yang terkait dalam kegiatan pengabdian kepada masyarakat ini.

\section{DAFTAR PUSTAKA}

Biofarmaka IPB. 2015. Tanaman Obat. Bogor: Pusat Studi Biofarmaka.

British Geriatrics Society. 2013. Guidance on the management of pain in older people. Oxford: Oxford University Press.

Geriatrics Subcommittee COC Internal Medicine Hospital Author. 2003. Clinical Guidelines on Geriatric Urinary Incontinence Society. Hongkong.

International Diabetes Federation. 2013. Managing older people with diabetes global guideline. International diabetes federation.
NIH Consensus Conference. 1998. Acupuncture. JAMA Vol 280: 1518-24. 